\title{
Effects of Static Magnetic Fields on the Physical, Mechanical, and Microstructural Properties of Cement Pastes
}

\author{
Juan J. Soto-Bernal, ${ }^{1}$ Rosario Gonzalez-Mota, ${ }^{1}$ \\ Iliana Rosales-Candelas, ${ }^{1}$ and Jose A. Ortiz-Lozano ${ }^{2}$ \\ ${ }^{1}$ Instituto Tecnológico de Aguascalientes, Avenida A. López Mateos 1801 Ote., 20256 Aguascalientes, AGS, Mexico \\ ${ }^{2}$ Department of Construction and Structures, Autonomous University of Aguascalientes, Avenida Universidad 940, \\ Module 108, 20131 Aguascalientes, AGS, Mexico
}

Correspondence should be addressed to Jose A. Ortiz-Lozano; jose.ortiz.lozano@gmail.com

Received 26 February 2015; Accepted 20 April 2015

Academic Editor: Santiago Garcia-Granda

\begin{abstract}
Copyright ( 2015 Juan J. Soto-Bernal et al. This is an open access article distributed under the Creative Commons Attribution License, which permits unrestricted use, distribution, and reproduction in any medium, provided the original work is properly cited.

This paper presents the results of an experimental study carried out to comprehend the physical, mechanical, and microstructural behavior of cement pastes subjected to static magnetic fields while hydrating and setting. The experimental methodology consisted in exposing fresh cement pastes to static magnetic fields at three different magnetic induction strengths: 19.07, 22.22, and 25.37 Gauss. The microstructural characterization makes evident that there are differences in relation to amount and morphology of CSH gel; the amount of $\mathrm{CSH}$ is larger and its morphology becomes denser and less porous with higher magnetostatic induction strengths; it also shows the evidence of changes in the mineralogical composition of the hydrated cement pastes. The temperature increasing has no negative effects over the cement paste compressive strength since the magnetostatic field affects the process of hydration through a molecular restructuring process, which makes cement pastes improve microstructurally, with a reduced porosity and a higher mechanical strength.
\end{abstract}

\section{Introduction}

Cement can be described as a material with both adhesive and cohesive properties, which gives it the ability to agglutinate mineral fragments. The methods or techniques that increase the adhesive and cohesive properties are sought continuously. A review of the theoretical and experimental studies related to hydration of cement and microstructure of hardened cement paste, mortar, and concrete is presented by [1].

It is well known that both the water presence and water transport play key roles in determining the pore structure and mechanical strength as well as long-term durability of cementitious materials. Magnetic treatment of water has been carried out in many studies to improve the properties of cementitious materials [2-6]. On the other hand, a magnetic field can accelerate the crystallization of sparingly soluble diamagnetic salts of weak acids like calcium carbonate [7] and gypsum [8]. There is a marked effect of magnetic field on the crystallization of calcium carbonate in ordinary water to $0.19 \mathrm{~T}$ [7] and an alignment of micron-sized crystals dispersed in fluid at room temperature; this is achieved below $2 \mathrm{~T}$ for gypsum [8].

In the work [9], the efficiency of adsorption with activated carbon under the influence of a magnetic field was evaluated as an alternative method to treat the contamination of water. Adsorptive tests at both presence and absence of the magnetic field were performed, having found that the magnetic field significantly influenced the adsorption, since gains obtained in adsorption of organic molecules using a magnetic field show that this kind of induction can be a good alternative to maximize adsorptive results.

The work [10] reported that concrete acquires natural remanent magnetization, due to the earth's magnetic field, at casting and presented measurements of the direction and intensity of magnetization in concrete samples with and without fly ash. 
The work [11] employed low field nuclear magnetic resonance (NMR) to investigate the water distribution and content in cement paste with different water-to-cement ratio during early and later hydration stages. Based on the connection between relaxation time and pore size, the relative content changes of water in various states and constrained in different types of pores were measured. The results demonstrate that it is influenced by the formation of pore system and the original water-to-cement ratio in the paste. Consequently, the relative content of capillary water was smaller in pastes with low $w / c$ ratios.

Four compounds are considered as the main components of Portland clinker: tricalcium silicate $\left(3 \mathrm{CaO} \cdot \mathrm{SiO}_{2}\right.$ $\left(\mathrm{C}_{3} \mathrm{~S}\right)$ ), dicalcium silicate $\left(2 \mathrm{CaO} \cdot \mathrm{SiO}_{2}\left(\mathrm{C}_{2} \mathrm{~S}\right)\right)$, tricalcium aluminate $\left(3 \mathrm{CaO} \cdot \mathrm{Al}_{2} \mathrm{O}_{3}\left(\mathrm{C}_{3} \mathrm{~A}\right)\right)$, and aluminoferrite tetracalcium ( $4 \mathrm{CaO} \cdot \mathrm{Al}_{2} \mathrm{O}_{3} \cdot \mathrm{Fe}_{2} \mathrm{O}_{3}\left(\mathrm{C}_{4} \mathrm{AF}\right)$ ). When Portland cement is mixed with water, its four crystallographic phases start to hydrate. The reaction of tricalcium aluminate $\left(\mathrm{C}_{3} \mathrm{~A}\right)$ and ferrite phase $\left(\mathrm{C}_{4} \mathrm{AF}\right)$ predominates at early ages of hydration. The reaction of calcium silicate phases $\left(\mathrm{C}_{3} \mathrm{~S}\right.$ and $\left.\beta-\mathrm{C}_{2} \mathrm{~S}\right)$ predominates from about the time of initial set going onward, forming calcium silicate hydrates and $\mathrm{Ca}(\mathrm{OH})_{2}[12,13]$.

Hydration is a heterogeneous process where there are at least two solid phases concerned, the initial (anhydrous) and final (hydrated) phases, and one liquid phase. According to the model documented by [14], the mechanism of hydration is based on the effect of saturation/supersaturation of $\mathrm{Ca}_{2}{ }^{+}$ ion on the hydration of $\mathrm{C}_{3} \mathrm{~S}$ particles, via assisting a morphological change from an impervious calcium silicate.

The effects of the treatment of fresh cement pastes with $\mathrm{CO}_{2}$ laser radiation $(10.6 \mu \mathrm{m})$, in order to improve its mechanical properties in addition to obtaining lower setting times than those of a natural setting (without radiation), were reported before [15]. Also, the changes that occurred in cement pastes irradiated by $10.6 \mu \mathrm{m} \mathrm{CO}$ laser at different stages of hydration after preparation by using Raman spectroscopy, X-ray diffraction, and Scanning Electronic Microscopy (SEM) techniques to observe molecular structural changes were presented [16].

Furthermore, the effects of a magnetic field on diamagnetic materials, like water, have been considered to occur by means of the magnetic orientation; influences of magnetic field on microscopic structures and macroscopic properties of water have been studied by the spectrum techniques of infrared, Raman, visible, ultraviolet lights and X-ray. References [17-19] have studied the influence of the magnetic field on physical-chemical properties of the liquid water. An external electric field influences the number of hydrogen bonds, the water structure, and the self-diffusion coefficient of the water molecules. The results suggest that the hydrogen bonds are broken, which increases the force of the remaining bonds. They conclude that the competition between different hydrogen bond networks (intra- and intermolecular) gives rise to the weakening of the intracluster hydrogen bonds, forming smaller clusters with stronger intercluster hydrogen bonds.

Magnetic field effects on liquid water have been studied from the Monte Carlo simulation in a lower magnetic field $(0.2 \mathrm{~T})$; also, the effect of an external magnetic field was reported on the internal energy and heat capacity of water [20].

In biochemical systems, the Larmor effect may provide a mechanism by which biological systems become sensitive to small static and alternating magnetic fields [21]. These direct effects of electromagnetic fields on single particles have been extensively studied in the classical case of the action of Lorentz's force on ions (e.g., $\mathrm{Ca}_{2}{ }^{+}$) [22]. The Lorentz model characterizes magnetic field effects on binding and transport of charge carriers via the magnetic Lorentz force. For a charged particle under viscous forces and a magnetic field, the equation of motion is [23]

$$
m \frac{d^{2} x}{d t^{2}}+m \beta \frac{d x}{d t}+q \frac{d x}{d t} \times B+F_{\text {end }}+F_{\text {noise }}=0
$$

where $x$ is the position vector; $m$ is the particle mass; $\beta$ is the viscous damping (due to thermal collisions); $q$ is the particle charge; $\mathbf{B}$ is the magnetic field vector; $F_{\text {end }}$ is the force due to binding site geometry and/or endogenous intermolecular forces; and $F_{\text {noise }}$ is the force due to thermal noise. The Lorentz model yields a lower limit in the mT-range (10-100 Gauss) for static magnetic field effects on ion binding kinetics [23].

Given a static magnetic field oriented along the $z$-axis, the Lorentz-Langevin equation may be written as follows $[22,24]$ :

$$
\frac{d^{2} r}{d t^{2}}=-\beta \frac{d r}{d t}+\gamma \frac{d r}{d t} \times B k-\omega^{2} r+n,
$$

where $r$ is the position vector of the particle, $\gamma$ is the ion charge-to-mass ratio $(q / m), k$ is the unit vector along the $z$-axis, $\omega$ is the angular frequency of the oscillator, and $n$ is the random thermal noise force per unit mass. The Lorentz equation yields a coherent solution describing precession of the bound-ion oscillator orientation at the Larmor frequency in an exogenous magnetic field [24]:

$$
\omega_{L}=\frac{\gamma B}{2} .
$$

This paper presents the results of an experimental study carried out to comprehend the physical, mechanical, and microstructural behavior of cement pastes under the influence of static magnetic fields while setting is taking place.

\section{Experimental Methodology}

2.1. Materials. The cement pastes were prepared with a composite Portland cement classified as CPC $30 \mathrm{R}$ pursuant to Mexican standard [25], with a 7-day compressive strength of $30 \mathrm{MPa}$; this is one of the most commonly used commercial cements in Mexico. Table 1 gives its chemical composition as well as its physical and mechanical properties.

\subsection{Mixture of Fresh Cement Pastes and Environmental Condi-} tions. The cement pastes were mixed as specified in standard [26] with a water/cement ratio of 0.50 . This $W / C$ ratio was chosen because it is the value specified for determining normal cement paste consistency in standard [27]. The hardened cement paste samples consisted of $75 \times 50 \mathrm{~mm}$ cylindrical 


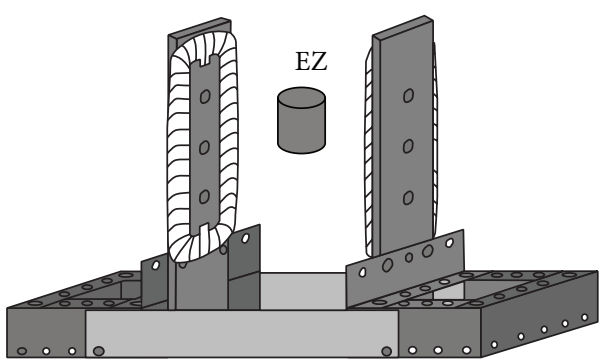

(a) Magnetostatic field generator

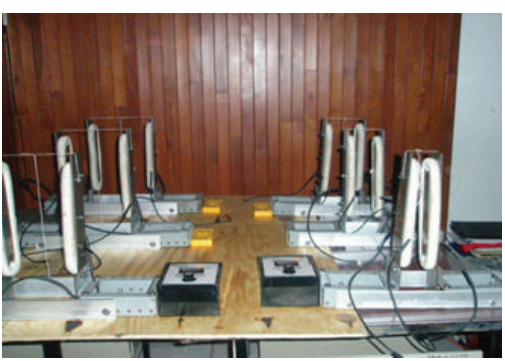

(b) Experimental setup

FIGURE 1: Details of the magnetostatic field generator and the experimental setup.

TABLE 1: Chemical composition and physical and mechanical properties of the cement used.

\begin{tabular}{|c|c|c|}
\hline Chemical analysis & $\begin{array}{c}\text { Specification } \\
\text { NMX-C-414-ONNCCE }\end{array}$ & Result \\
\hline $\mathrm{SiO}_{2}$ & - & 22.97 \\
\hline $\mathrm{Al}_{2} \mathrm{O}_{3}$ & - & 4.53 \\
\hline $\mathrm{Fe}_{2} \mathrm{O}_{3}$ & - & 2.72 \\
\hline $\mathrm{CaOt}$ & - & 61.38 \\
\hline $\mathrm{CaOL}$ & - & 0.47 \\
\hline $\mathrm{MgO}$ & - & 1.46 \\
\hline $\mathrm{SO}_{3}$ & $4.0 \% \max$. & 2.61 \\
\hline R.I. & - & 8.14 \\
\hline $\mathrm{Na}_{2} \mathrm{O}$ & - & 0.65 \\
\hline $\mathrm{K}_{2} \mathrm{O}$ & - & 1.10 \\
\hline Blaine $\left(\mathrm{cm}^{2} / \mathrm{g}\right)$ & - & 4327 \\
\hline $\begin{array}{l}\% \text { Fineness sieve size } \\
325(45 \mu \mathrm{m})\end{array}$ & - & 1.60 \\
\hline \multicolumn{3}{|l|}{ Sanity } \\
\hline Expansion & $0.80 \% \max$. & - \\
\hline Shrinkage & $0.20 \%$ max. & -0.03 \\
\hline \multicolumn{3}{|l|}{$\begin{array}{l}\text { Time of setting by } \\
\text { Vicat needle (min) }\end{array}$} \\
\hline Initial & $45 \mathrm{~min}$. & 192 \\
\hline Final & 375 max. & 313 \\
\hline False set $\%$ & - & 79 \\
\hline \multicolumn{3}{|l|}{$\begin{array}{l}\text { Compressive strength } \\
\left(\mathrm{N} / \mathrm{mm}^{2}\right)\end{array}$} \\
\hline 1 day & - & 16.9 \\
\hline 3 days & $20 \mathrm{~min}$. & 28.8 \\
\hline 7 days & - & 34.9 \\
\hline 28 days & $30-50$ & 40.8 \\
\hline
\end{tabular}

specimens. The experimental tests were carried out in a closed laboratory in which the environmental conditions (temperature and relative humidity) were controlled and were registered consistently; the environmental temperature during the tests ranged between 18 and $22^{\circ} \mathrm{C}$.
2.3. Exposure of the Specimens to Static Magnetic Fields. The experimental methodology consisted in assessing the fresh cement pastes setting times as well as compressive strength at, respectively, 24 hours, 3 days, and 7 days of hardened cement paste samples. Such samples were exposed to a treatment of static magnetic fields at three different magnetic induction strengths immediately after being mixed, during 24 hours. Later on, the samples were stored for curing in wet environmental conditions: temperature of $20^{\circ} \mathrm{C}$ and relative humidity higher than $95 \%$.

Alongside, some other cement pastes samples were mixed and casted without having been subjected to static magnetic fields, in order to take them as comparative reference. In the case of microstructural characterization by means of Raman spectroscopy, some samples were characterized after 24 hours after they have been mixed and others were treated 7 days after they hardened in order to test out that magnetization posterior to that time length has no effects on hardened cement paste microstructure.

2.3.1. Magnetostatic Field Generator. A magnetostatic field generator (MFG) was made in order to obtain magnetic field strengths of 0 to 30 Gauss in the exposure zone (EZ). The MFG consists of a ferromagnetic rectangular core (iron) (25 $\times 10 \mathrm{~cm}$ ), surrounded by a coil (insulated solid copper wire of 400 turns), with a current intensity of $3 \mathrm{~A}$ and voltage from 0 to $30 \mathrm{~V}$. The magnetic field strength $\left(\mathbf{B}_{\mathbf{z}}\right)$ was measured every $1 \mathrm{~cm}$ along the $z$-axial direction by using a gauss meter ( $\mathrm{F}$. W. BELL, Model 5180). The details of the magnetostatic field generator and the experimental setup are shown in Figures 1(a) and $1(\mathrm{~b})$.

2.3.2. Temperature Measurements. Sample temperatures were taken on the surface of both specimens with exposition and without exposition to magnetostatic fields, with a Fluke 63 infrared thermometer at 8-hour intervals from the time where they were prepared until the respective characterization trials began.

\subsection{Characterization Tests of Fresh Cement Paste Samples}

2.4.1. Setting Times. Setting times were monitored in all the cement pastes samples with a Vicat apparatus, according to standard [28]. 


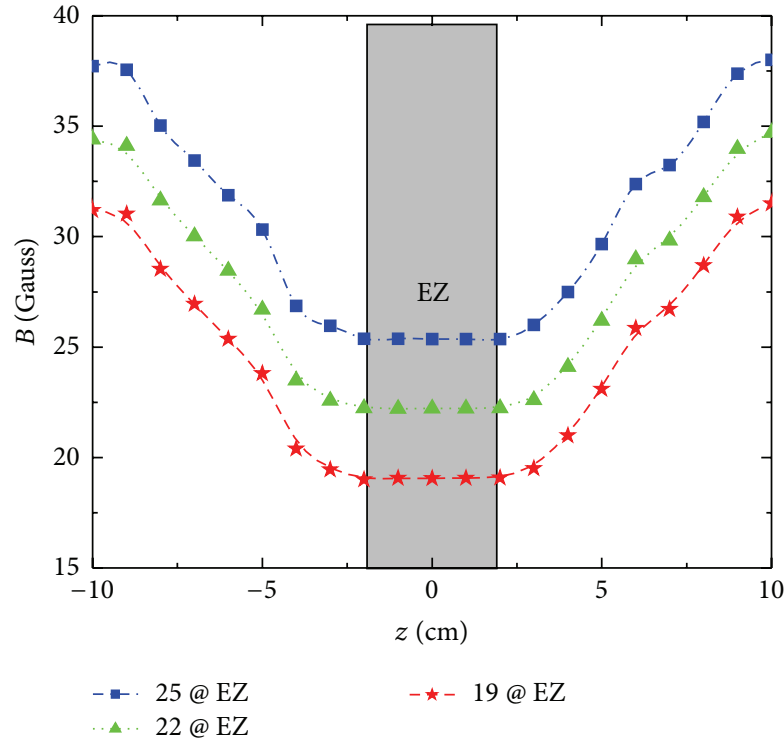

Figure 2: Axial magnetic field distributions measured along the $z$ axis direction; $\mathrm{EZ}$ is the exposure zone.

\subsection{Characterization Tests of Hardened Cement Paste Samples}

2.5.1. Compressive Strength. Five $75 \times 50 \mathrm{~mm}$ cylindrical specimens were prepared for each magnetic field strength (B) in order to test them for compressive strength at 24 hours and 3 and 7 days.

2.6. Microstructure Characterization Tests of Hardened Cement Paste Samples. Magnetic treated samples were characterized by Raman spectroscopy and Scanning Electronic Microscopy (SEM). Profile intensity changes were recorded in the Raman spectra of the cement paste samples after magnetic treatment. Raman spectra were taken with a Renishaw model 1000 Raman spectrometer (excitation wavelength of $830 \mathrm{~nm}$ ) for all samples. Several spectra (up to 5) were taken and averaged for samples of a given laser treatment and age. SEM micrographs were taken from the surface of the cement paste samples after magnetic treatment with a XL30 SEM equipped with an EDX spectrometer for X-ray dispersion elemental analysis.

\section{Results and Analysis}

The magnetic field strengths in the axial direction were measured (Figure 2). The exposure zone (EZ) of $B_{\min }$ (19.07, 22.22, and 25.37 Gauss) is achieved over a length of $50 \mathrm{~mm}$, which is the expected value.

\subsection{Temperature Evolution of Fresh Cement Paste Samples.} During the process of exposure to magnetostatic fields, the temperature of samples was taken on the surface for each magnetic induction strength, including the sample with no magnetic treatment. The results are shown in Figure 3.

We can observe in the previous figure that a temperature increase is taking place in cement paste samples due to

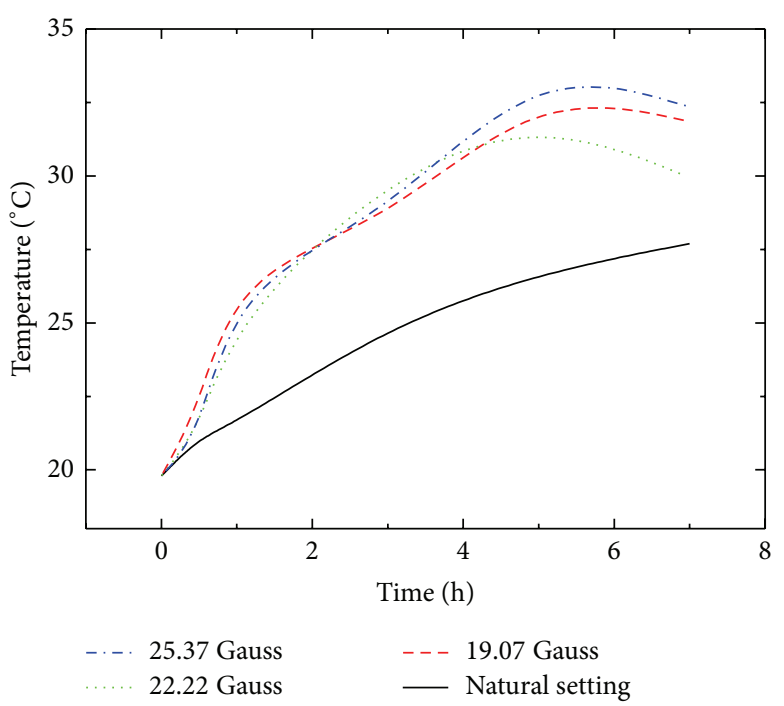

FIGURE 3: Surface temperature of fresh cement pastes during the exposure to magnetostatic fields.

exothermic chemical reactions of hydration; however, an additional temperature increase is also observed due to magnetostatic exposure. In fact, the higher the magnetic induction strength, the higher the heat developed by cement paste sample.

On the one hand, the mechanism of hydration is based on the effect of saturation/supersaturation of $\mathrm{Ca}_{2}{ }^{+}$ion on the hydration of $\mathrm{C}_{3} \mathrm{~S}$ particles, via assisting a morphological change from an impervious calcium silicate.

The reaction of calcium silicate phases $\left(\mathrm{C}_{3} \mathrm{~S}\right.$ and $\left.\beta-\mathrm{C}_{2} \mathrm{~S}\right)$ predominates from about the time of initial set going onward, forming calcium silicate hydrates and $\mathrm{Ca}(\mathrm{OH})_{2}$. On the other hand, $\mathrm{C}_{3} \mathrm{~A}$ liberates a large amount of heat during first few days.

In biochemical systems [23] posit that the effect of the magnetic field is to induce precessional motion at the Larmor frequency in bound water molecules forming hydration layers at the binding site.

What is mentioned above implies that the magnetostatic treatment affects the cement rate of hydration, accelerating it. As well as the cement heat of hydration, since the magnetostatic field is not generating heat over the sample, but the temperature increasing is due to the magnetic field propagation on water phases when cement starts to hydrate.

3.2. Setting Times. Setting times results are presented in Figure 4, for all of the samples of cement paste.

The setting curves show the inverse relationship between the magnetic induction strength and the setting times; that is to say, the higher the magnetic induction strength, the faster the cement pastes set. These trends agree with the temperature evolution curves presented before.

When cement is in contact with water, $\mathrm{C}_{3} \mathrm{~S}$ dissolves [29] and $\mathrm{Ca}_{2}{ }^{+}$ions go into the solution and then adsorb it at the surface, so the cement becomes positively charged [12], and calcium, silicate, and hydroxide concentrations increase in 


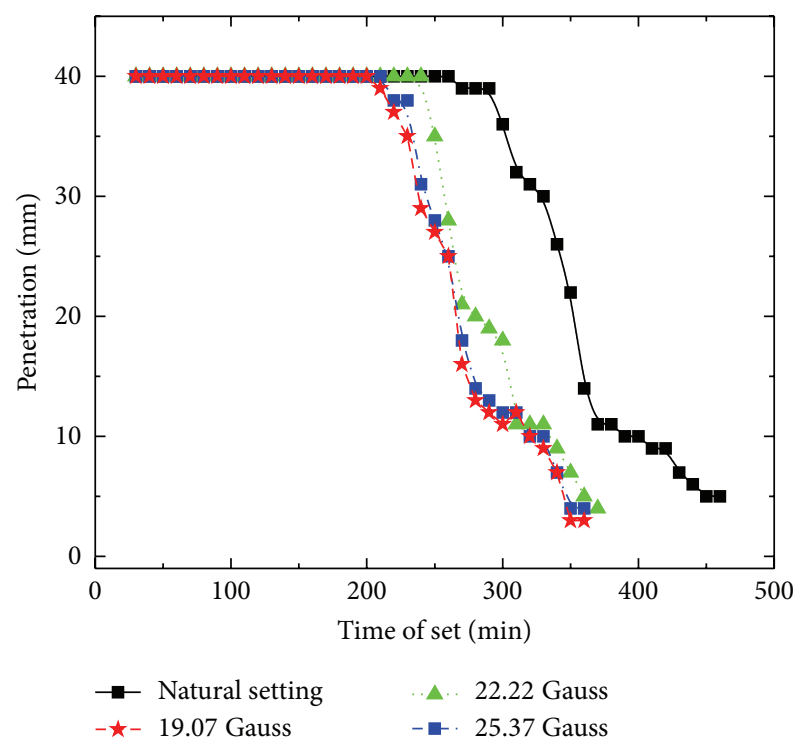

FIgURE 4: Setting times for the cement pastes.

solution, decreasing the degree of undersaturation and therefore the rate.

The reaction of tricalcium aluminate $\left(\mathrm{C}_{3} \mathrm{~A}\right)$ and ferrite phase $\left(\mathrm{C}_{4} \mathrm{AF}\right)$ predominates at early stages of hydration. The reaction of calcium silicate phases $\left(\mathrm{C}_{3} \mathrm{~S}\right.$ and $\left.\beta-\mathrm{C}_{2} \mathrm{~S}\right)$ predominates from about the time of initial set going onward, forming calcium silicate hydrates and $\mathrm{Ca}(\mathrm{OH})_{2}$ molecules, which are arranged around functional groups of the binder. If the magnetostatic treatment affects the cement rate of hydration, accelerating it, and also the cement heat of hydration, then temperature, the rate of initial hydration of cement phases, and the rate of formation of hydration products are increased as well.

3.3. Compressive Strength. The compressive strength results are presented in Figure 5.

We can acknowledge the favorable effect of magnetic induction over the compressive strength values of the cement pastes, obtaining the higher values with the higher magnetic induction strengths. For example, the compressive strength at 7 days of the cement paste treated with 25.37 Gauss increased its compressive strength of $13 \%$ in relation to the natural setting paste, having passed from 18.6 to $21.1 \mathrm{MPa}$. It is well known that an increase in the early curing temperature makes the hydration rate and cement strength increase rapidly, but due to the nonhomogeneous diffusion of the hydration products the porosity of the cement paste increases and microcracks develop, which finally leads to decreased strength at a later time [30].

Although a higher temperature during placing and setting increases strength in the very early stages, it may adversely affect the strength from about 7 days going onwards. The explanation for this is that rapid initial hydration appears to form products of a poorer physical structure, which are probably more porous, so a proportion of the pores always remain unfilled.

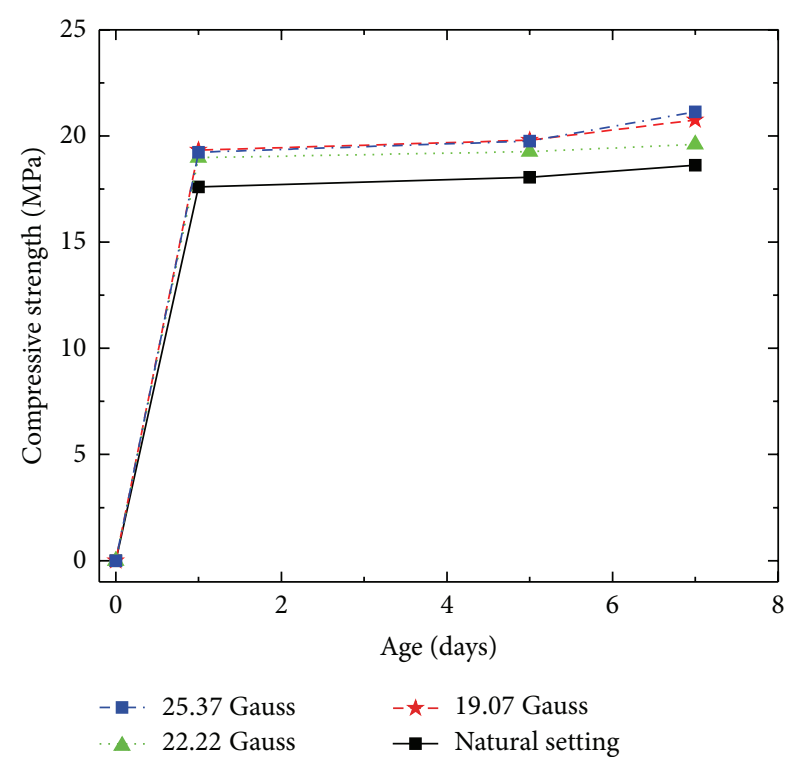

FIGURE 5: Compressive strength of cement pastes for each magnetic induction strength.

It follows from the gel/space ratio rule that this would lead to a lower strength than that of a less porous but slowly hydrating cement paste, in which a high gel/space ratio would eventually be reached.

This explanation of the adverse effects of a high early temperature on later strengths has been extended by [31], suggesting that a rapid initial rate of hydration at higher temperatures slows hydration down and produces a nonuniform distribution of the products of hydration within the paste. The reason for this is that, at the high initial rate of hydration, there is insufficient time for the diffusion of the products of hydration away from the cement particles and for a uniform precipitation in the interstitial space (as it is the case at lower temperatures). As a result, a high concentration of the products of hydration builds up in the vicinity of the hydrating particles, and this subsequently slows hydration down and has an adverse effect on long-term strength.

In addition, the nonuniform distribution of the products of hydration adversely affects the strength per se because the $\mathrm{gel} /$ space ratio is lower than it would otherwise be the case for an equal degree of hydration, and the weaker local areas lower the overall strength of the hydrated cement paste [32].

Nevertheless, it can be seen that, in this case, the temperature increasing has no negative effects over the cement paste compressive strength since the magnetostatic field affects the process of hydration through a molecular restructuring process, which leads to microstructurally improved cement pastes, with a reduced porosity and a higher mechanical strength.

\subsection{Microstructure Characterization Tests of Hardened Cement Paste Samples}

3.4.1. Raman Spectroscopy. The results corresponding to microstructural characterization by means of Raman spectra 


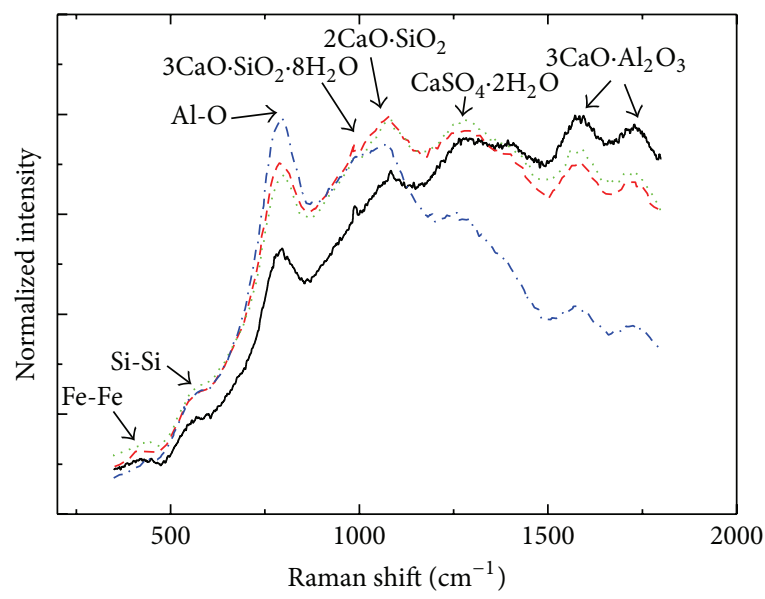

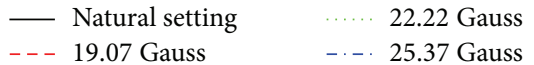

(a)

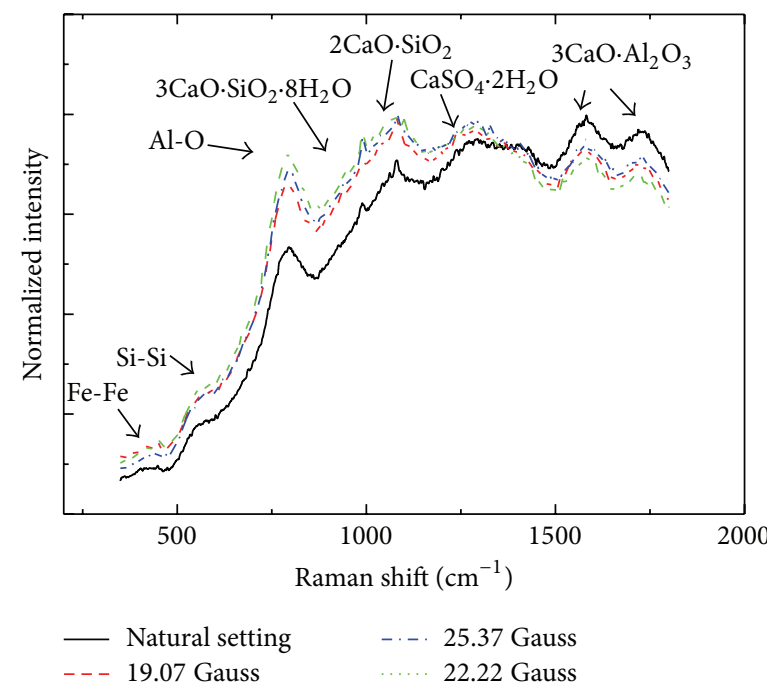

(b)

FIGURE 6: Raman spectra of cement pastes exposed to magnetostatic fields: (a) after 24 hours after mixing and (b) after 7 days after hardening.

are presented in Figures 6(a) and 6(b), for the cement pastes treated with magnetic induction. As stated in the experimental methodology section, the samples were characterized after 24 hours and 7 days.

Changes can be observed in the main compounds in magnetized cement pastes. The $\mathrm{Al}-\mathrm{O}$ bond (aluminum and oxygen) can be located at $790 \mathrm{~cm}^{-1}$ peak; the peak located in the wavenumber of $987 \mathrm{~cm}^{-1}$ corresponds with the tricalcium silicate $\left(3 \mathrm{CaO} \cdot \mathrm{SiO}_{2} \cdot 8 \mathrm{H}_{2} \mathrm{O}\right)$, which is derived from the alite, a main constituent of Portland cement and responsible for early age strength. In the wavenumber of $1078 \mathrm{~cm}^{-1}$ we can identify the creation of dicalcium silicate $\left(2 \mathrm{CaO} \cdot \mathrm{SiO}_{2}\right)$ which is known as belite, also a Portland cement main constituent and responsible for the long-term mechanical strength, as well as the gypsum $\left(\mathrm{CaSO}_{4} \cdot 2 \mathrm{H}_{2} \mathrm{O}\right)$ which is located in the $1279 \mathrm{~cm}^{-1}$ peak. Finally the tricalcium aluminate $\left(3 \mathrm{CaO} \cdot \mathrm{Al}_{2} \mathrm{O}_{3}\right)$, also a main constituent of Portland cement and in charge of instant set and very early strength, is located in the peaks of wavenumber of $1581 \mathrm{~cm}^{-1}$ and $1732 \mathrm{~cm}^{-1}$ [16].

Taking into account that the fluorescence can give anomalous results, we can see that the bands attributed to main compounds in hydrated cement paste are increased or decreased due to the effect of magnetostatic induction and due to the effect of the strength therefore, that is, the higher the magnetostatic induction strength, the higher the increment in creation of those compounds.

Likewise, it can be observed that, after 7 days, the effect of magnetic treatment has no effect over the hardened cement paste, in which it is no longer possible to modify its microstructure morphologically. In a previous paper, it was concluded that a magnetic field accelerates the crystallization of sparingly soluble diamagnetic salts of weak acids, to which category calcium carbonate belongs [7].

3.4.2. Scanning Electronic Microscopy (SEM) and Elemental Analysis. The microscopic images taken by means of SEM are

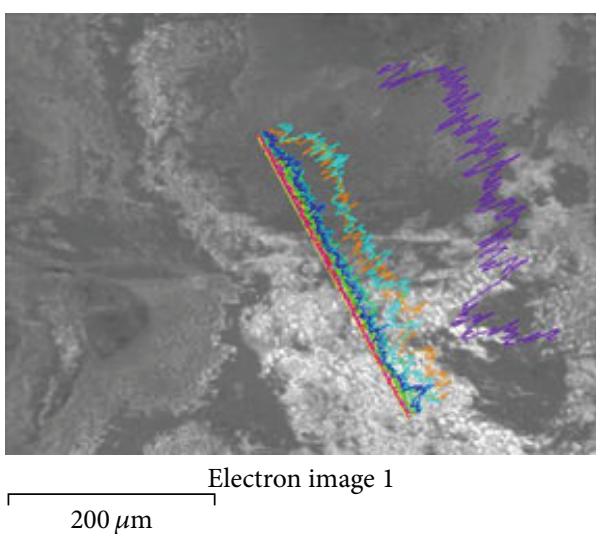

Figure 7: Appearance of cement paste sample without magnetic treatment.

presented in the Figures 7 and 8 . Figure 7 corresponds to the natural cement paste (without magnetic treatment) and Figures $8(\mathrm{a}), 8(\mathrm{~b})$, and $8(\mathrm{c})$, corresponding to hardened cement pastes treated with three magnetic induction strengths: 19.07, 22.22, and 25.37 Gauss, respectively.

The microscopic pictures presented before demonstrate certain differences in relation to amount and morphology of $\mathrm{CSH}$ (Calcium Silicate Hydrate) gel, main hydration product of cement and responsible for mechanical strength development.

It can be seen that the amount of CSH gel is larger and its morphology becomes denser and less porous with higher magnetostatic induction strengths; this fact favors the mechanical strength development, agreeing with the mechanical strength characterization results presented above.

On the other hand, the most marked differences among the four pastes consisted in the creation of the crystalline phases, which demonstrate the existence of different 

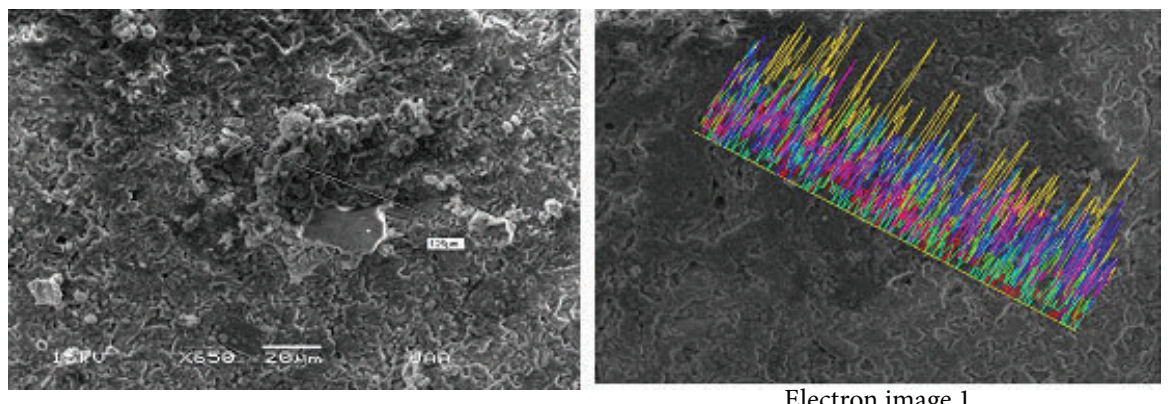

Electron image 1

$90 \mu \mathrm{m}$

(a) 19.07 Gauss
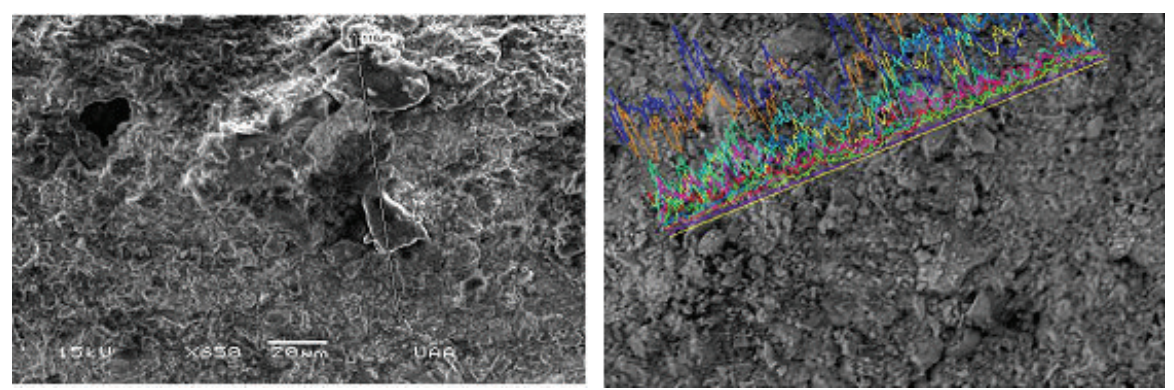

Electron image 1

$90 \mu \mathrm{m}$

(b) 22.22 Gauss
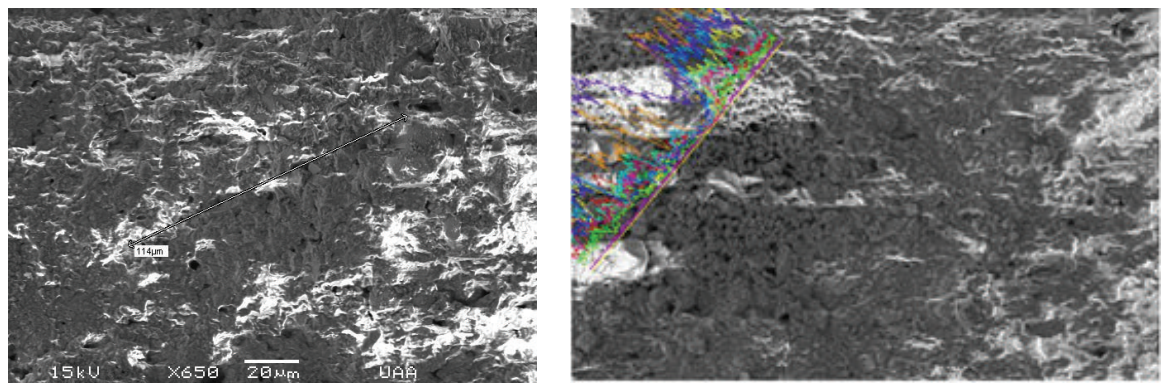

(c) 25.37 Gauss

FIgURE 8: Appearance of cement paste samples with different magnetic field strengths.

processes of crystallization, and the influence of the magnetostatic induction strength in the chemical reactions of cement hydration.

In Table 2, the elemental composition of hydrated cement pastes subjected to different magnetostatic induction strengths is presented, including the sample without treatment.

From Table 2, we can observe the evidence of changes in the mineralogical composition of the hydrated cement pastes subjected to magnetostatic treatment; for example, there is an increase in the calcium carbonate content as a result of the increase in the induction strength, which concords with other characterization results presented before, regarding physical, mechanical, and microstructural properties. Over again, the sample corresponding to the magnetic induction strength of 19.07 Gauss presents an anomalous behavior in $\mathrm{CaCO}_{3}$ compound. This could be explained due to the effect of saturation/supersaturation of $\mathrm{Ca}_{2}{ }^{+}$ion on the hydration of $\mathrm{C}_{3} \mathrm{~S}$ particles coupled with the precession of the boundion oscillator orientation at the Larmor frequency in an exogenous magnetic field.

\section{Conclusions}

Based on the experimental results, the magnetostatic treatment affects the cement rate of hydration, accelerating it, and also the cement heat of hydration; also it increases the temperature of cement paste samples. Regarding setting times, the higher the magnetic induction strength, the faster the cement pastes set; these trends agree with heat evolution curves.

The magnetostatic induction has favorable effects over the mechanical strength of cement paste, since the higher values of compressive strength were attained for the cement pastes 
TABLE 2: Elemental composition of cement paste samples under different magnetostatic induction strengths.

\begin{tabular}{lcccc}
\hline \multirow{2}{*}{ Compound } & \multicolumn{4}{c}{ \% Mass } \\
& $0.00 \mathrm{G}$ & $19.07 \mathrm{G}$ & $22.22 \mathrm{G}$ & $25.37 \mathrm{G}$ \\
\hline $\mathrm{CaCO}_{3}$ & 5.00 & 16.18 & 9.84 & 9.54 \\
$\mathrm{SiO}_{2}$ & 49.93 & 48.29 & 49.16 & 51.40 \\
$\mathrm{Albite}$ & 1.45 & 7.22 & 6.38 & 5.11 \\
$\mathrm{MgO}$ & 0.54 & 0.00 & 0.26 & 0.31 \\
$\mathrm{Al}_{2} \mathrm{O}_{3}$ & 1.44 & 0.00 & 0.73 & 0.68 \\
$\mathrm{Si}$ & 5.60 & 1.25 & 3.05 & 2.80 \\
$\mathrm{FeS}_{2}$ & 1.62 & 8.54 & 6.56 & 5.80 \\
$\mathrm{MAD} 10$ Feldspar & 1.07 & 9.48 & 5.60 & 5.72 \\
$\mathrm{Wollastonite}_{\mathrm{Fe}}$ & 29.40 & 9.04 & 17.11 & 18.00 \\
$\mathrm{SrF}$ & 0.91 & 0.00 & 0.32 & 0.29 \\
$\mathrm{Sn}$ & 0.00 & 0.00 & 0.29 & 0.37 \\
$\mathrm{~F}$ & 0.00 & 0.00 & 0.70 & 0.00 \\
$\mathrm{Yb}$ & 2.12 & 0.00 & 0.00 & 0.00 \\
\hline
\end{tabular}

treated with higher magnetic induction strengths; a relative increase of about $13 \%$ has been observed for the maximum induction strength at 7 days.

The temperature increasing has no negative effects over the cement paste compressive strength since the magnetostatic field affects the process of hydration through a molecular restructuring process, which leads to microstructurally improved cement pastes, with a reduced porosity and a higher mechanical strength.

The results corresponding to the microstructural characterization, by means of Raman, show that the bands attributed to main compounds in hydrated cement paste are increased or decreased due to the effect of magnetostatic induction and due to the effect of the strength; that is, the higher the magnetostatic induction strength, the higher the increment in creation of those compounds; the effect of magnetic treatment has no effect over the hardened cement paste after 7 days, since it is no longer possible to modify its microstructure morphologically.

The SEM pictures make evident certain differences in relation to amount and morphology of CSH gel, knowing that the amount of CSH gel is larger and its morphology becomes denser and less porous with higher magnetostatic induction strengths; this fact favors the mechanical strength development, agreeing with the mechanical strength characterization results. Likewise, the crystalline phases and the processes of crystallization were influenced by the magnetostatic induction strengths, through the reactions of cement hydration. SEM also shows the evidence of changes in the mineralogical composition of the hydrated cement pastes subjected to magnetostatic treatment, having increments in certain compounds such as calcium carbonate, for higher magnetic induction strengths.

It is not clear how the magnetostatic field affects the process of hydration, but a possible explanation could be related to the classical case of the action of Lorentz's force on ions because the effect of the external magnetic field is to induce the precessional motion at the Larmor frequency in bound water molecules forming hydration layers at the binding site. What is stated above can be explained since there is a great relationship among rate of hydration, heat of hydration, porosity, strength development, chemical composition, and morphology of $\mathrm{CSH}$ gel; when cement is in contact with water, $\mathrm{C}_{3} \mathrm{~S}$ dissolves and $\mathrm{Ca}_{2}{ }^{+}$ions go into the solution and then are being adsorbed at the surface. Due to such mechanisms, a molecular restructuring process is created, caused by the effects of magnetostatic treatment, which leads to microstructurally improved cement pastes, with a reduced porosity and a higher mechanical strength.

The reaction of tricalcium aluminate $\left(\mathrm{C}_{3} \mathrm{~A}\right)$ and ferrite phase $\left(\mathrm{C}_{4} \mathrm{AF}\right)$ predominates at early ages of hydration. The reaction of calcium silicate phases $\left(\mathrm{C}_{3} \mathrm{~S}\right.$ and $\left.\beta-\mathrm{C}_{2} \mathrm{~S}\right)$ predominates from about the time of initial set going onward, forming calcium silicate hydrates and $\mathrm{Ca}(\mathrm{OH})_{2}$ molecules, which are arranged around functional groups of the binder. This is the explanation why magnetostatic fields only affect fresh cement pastes.

\section{Conflict of Interests}

The authors declare that there is no conflict of interests regarding the publication of this paper.

\section{Acknowledgment}

The authors would like to express their gratitude to Maribel Diaz Juarez for her assistance in experimental procedures.

\section{References}

[1] J. Stark, "Recent advances in the field of cement hydration and microstructure analysis," Cement and Concrete Research, vol. 41, no. 7, pp. 666-678, 2011.

[2] N. Su and C.-F. Wu, "Effect of magnetic field treated water on mortar and concrete containing fly ash," Cement and Concrete Composites, vol. 25, pp. 681-688, 2002.

[3] V. V. Azharonok, N. K. Belous, S. P. Rodtsevich et al., "Highfrequency magnetic-pulse treatment of water as a method of improving the technological properties of fine concretes," Journal of Engineering Physics and Thermophysics, vol. 82, no. 6, pp. 1102-1109, 2009.

[4] N. K. Belous, V. V. Azharonok, S. P. Rodtsevich et al., "Influence of magnetic and acoustic treatment of superplasticizer solutions on the properties of portland cement concretes," Journal of Engineering Physics and Thermophysics, vol. 85, no. 3, pp. 493$500,2012$.

[5] J. Boguszynska, M. C. A. Brown, P. J. McDonald et al., "Magnetic resonance studies of cement based materials in inhomogeneous magnetic fields," Cement and Concrete Research, vol. 35, no. 10, pp. 2033-2040, 2005.

[6] N. Su, Y.-H. Wu, and C.-Y. Mar, "Effect of magnetic water on the engineering properties of concrete containing granulated blastfurnace slag," Cement and Concrete Research, vol. 30, no. 4, pp. 599-605, 2000.

[7] H. E. L. Madsen, "Crystallization of calcium carbonate in magnetic field in ordinary and heavy water," Journal of Crystal Growth, vol. 267, no. 1-2, pp. 251-255, 2004. 
[8] C. Uyeda, S. Kano, K. Hisayoshi, A. Nakanishi, and K. Kimoto, "Efficiency of magnetic alignment found in various paramagnetic and diamagnetic solids detected by simple rotational oscillation of sample in microgravity," Materials Transactions, vol. 48, no. 11, pp. 2893-2897, 2007.

[9] J. F. de Brito, L. D. O. Ferreira, M. C. R. Pereira, J. P. da Silva, and T. C. Ramalho, "Adsorption of aromatic compounds under magnetic field influence," Water, Air, \& Soil Pollution, vol. 223, no. 6, pp. 3545-3551, 2012.

[10] C. W. Farrell, "Natural remanent magnetization of Portland cement concrete," Cement and Concrete Research, vol. 21, pp. 489-495, 1991.

[11] A.-M. She, W. Yao, and W.-C. Yuan, "Evolution of distribution and content of water in cement paste by low field nuclear magnetic resonance," Journal of Central South University, vol. 20, no. 4, pp. 1109-1114, 2013.

[12] M. Heikal, M. S. Morsy, and I. Aiad, "Effect of treatment temperature on the early hydration characteristics of superplasticized silica fume blended cement pastes," Cement and Concrete Research, vol. 35, no. 4, pp. 680-687, 2005.

[13] A. M. Neville, Properties of Concrete, Pearson Education, London, UK, 4th edition, 1999.

[14] H. F. W. Taylor, Cement Chemistry, Thomas Telford, London, UK, 2nd edition, 1997.

[15] M. R. Moreno-Virgen, J. J. Soto-Bernal, J. A. Ortiz-Lozano et al., "Effect of $\mathrm{CO}_{2}$ laser radiation on the mechanical properties of Portland cement pastes," Materiales de Construccion, vol. 61, no. 301, pp. 77-91, 2011.

[16] M. R. Moreno-Virgen, J. J. Soto-Bernal, J. A. Ortiz-Lozano et al., "Laser radiation $\mathrm{CO}_{2}$ effects in cement paste at different hydration stages after preparation," Ingeniería Investigación y Tecnología, vol. 12, pp. 321-328, 2011.

[17] X.-F. Pang and D. Bo, "The changes of macroscopic features and microscopic structures of water under influence of magnetic field," Physica B: Condensed Matter, vol. 403, no. 19-20, pp. 35713577, 2008.

[18] E. J. L. Toledo, T. C. Ramalho, and Z. M. Magriotis, "Influence of magnetic field on physical-chemical properties of the liquid water: insights from experimental and theoretical models," Journal of Molecular Structure, vol. 888, no. 1-3, pp. 409-415, 2008.

[19] E. J. L. Toledo, R. Custodio, T. C. Ramalho, M. E. G. Porto, and Z. M. Magriotis, "Electrical field effects on dipole moment, structure and energetic of $\left(\mathrm{H}_{2} \mathrm{O}\right)_{n}(2 \leq n \leq 15)$ cluster," Journal of Molecular Structure: THEOCHEM, vol. 915, no. 1-3, pp. 170-177, 2009.

[20] K. X. Zhou, G. W. Lu, Q. C. Zhou, J. H. Song, S. T. Jiang, and H. R. Xia, "Monte Carlo simulation of liquid water in a magnetic field," Journal of Applied Physics, vol. 88, no. 4, pp. 1802-1805, 2000.

[21] D. T. Edmonds, "Larmor precession as a mechanism for the detection of static and alternating magnetic fields," Bioelectrochemistry and Bioenergetics, vol. 30, pp. 3-12, 1993.

[22] B. Bianco and A. Chiabrera, "From the Langevin-Lorentz to the Zeeman model of electromagnetic effects on ligand-receptor binding," Bioelectrochemistry and Bioenergetics, vol. 28, no. 1-2, pp. 355-365, 1992.

[23] A. A. Pilla, D. J. Muehsam, and M. S. Markov, "A dynamical systems/Larmor precession model for weak magnetic field bioeffects: ion binding and orientation of bound water molecules," Bioelectrochemistry and Bioenergetics, vol. 43, no. 2, pp. 239-249, 1997.
[24] D. J. Muehsam and A. A. Pilla, "Lorentz approach to static magnetic field effects on bound-ion dynamics and binding kinetics: thermal noise considerations," Bioelectromagnetics, vol. 17, no. 2, pp. 89-99, 1996.

[25] Organismo Nacional de Normalización y Certificación de la Construcción y Edificación, NMX-C-414-ONNCCE Industria de la Construcción-Cementos Hidráulicos-Especificaciones y Métodos de Prueba, Organismo Nacional de Normalización y Certificación de la Construcción y Edificación, S.C., Mexico City, México, 2004.

[26] American Society for Testing and Materials, "Practice for mechanical mixing of hydraulic cement pastes and mortars of plastic consistency," ASTM C305-99e1, American Society for Testing and Materials, 2001.

[27] American Society for Testing and Materials, "Standard test method for normal consistency of hydraulic cement," ASTM C187-98, American Society for Testing and Materials, 2001.

[28] American Society for Testing and Materials, ASTM C191-99 Standard Test Method for Time of Setting of Hydraulic Cement by Vicat Needle, American Society for Testing and Materials, West Conshohocken, Pa, USA, 2001.

[29] K. L. Scrivener and A. Nonat, "Hydration of cementitious materials, present and future," Cement and Concrete Research, vol. 41, no. 7, pp. 651-665, 2011.

[30] J.-K. Kim, Y.-H. Moon, and S.-H. Eo, "Compressive strength development of concrete with different curing time and temperature," Cement and Concrete Research, vol. 28, pp. 1761-1773, 1998.

[31] J. G. Verbeck and R. H. Helmuth, "Structure and physical properties of cement pastes," in Proceedings of the 5th International Congress on the Chemistry of Cement, pp. 1-32, Tokyo, Japan, October 1968.

[32] J. Ortiz, A. Aguado, L. Agulló, and T. García, "Influence of environmental temperatures on the concrete compressive strength: simulation of hot and cold weather conditions," Cement and Concrete Research, vol. 35, no. 10, pp. 1970-1979, 2005. 

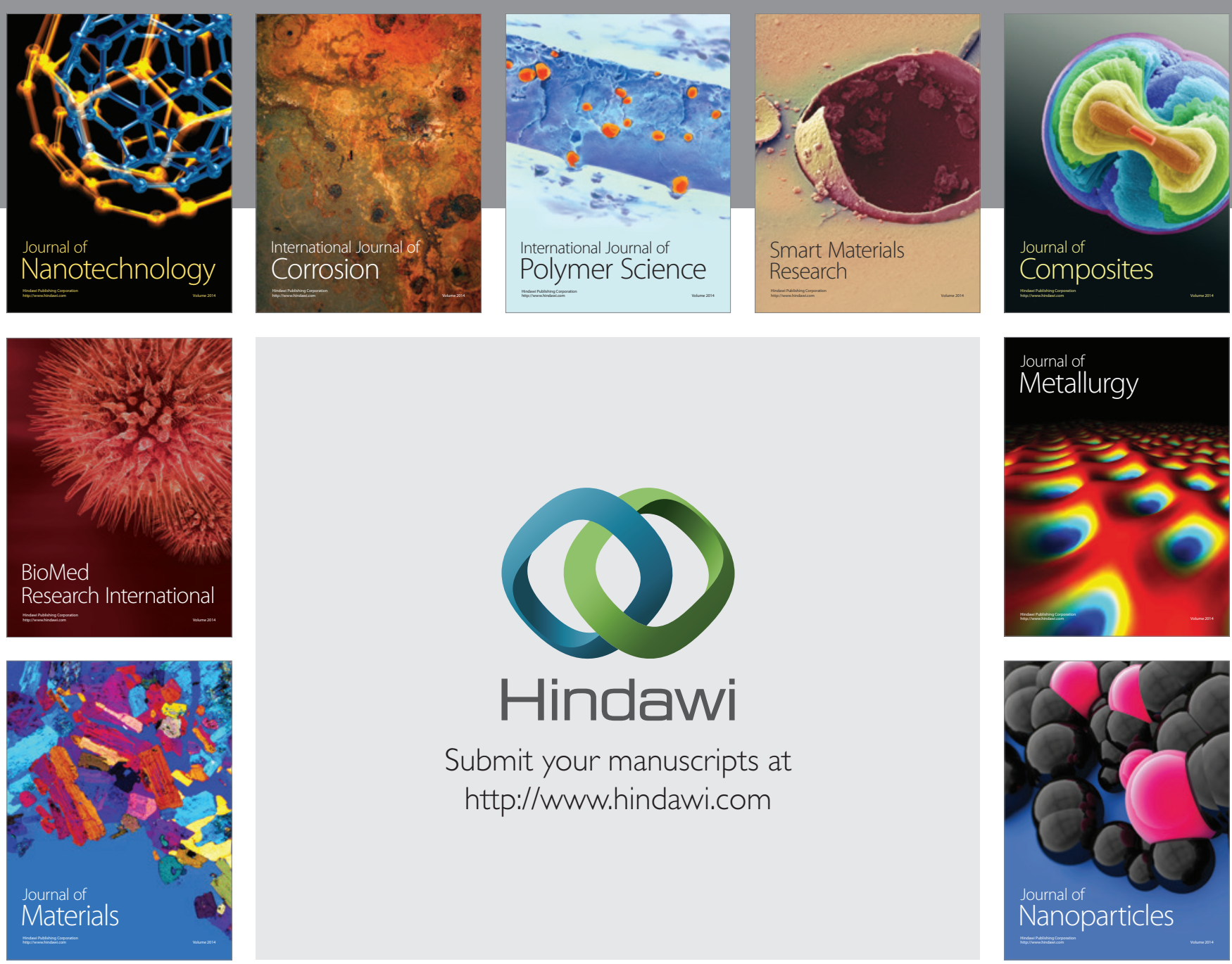

Submit your manuscripts at http://www.hindawi.com
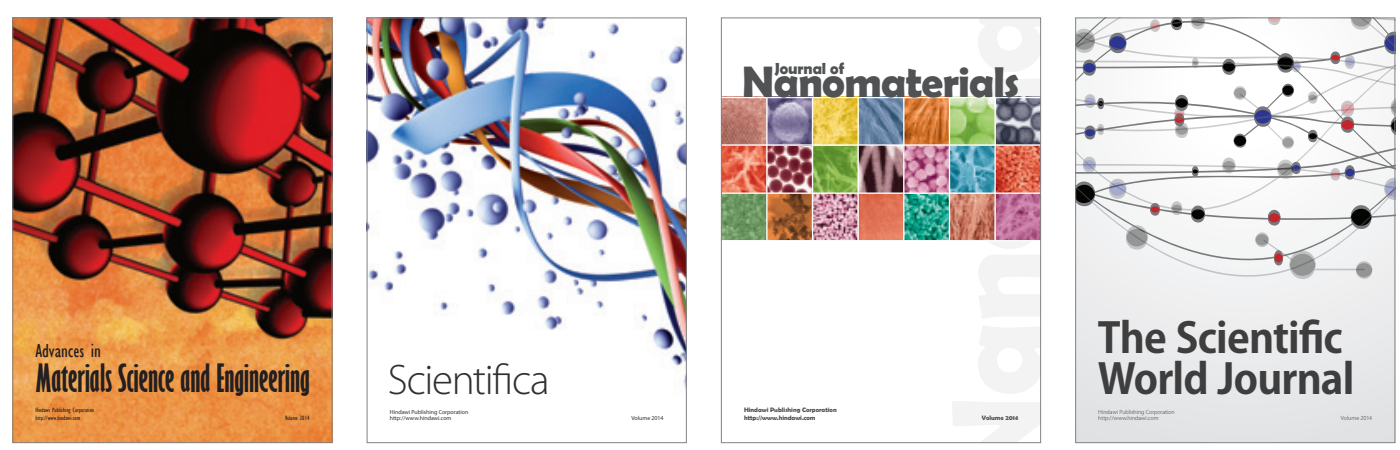

\section{The Scientific World Journal}
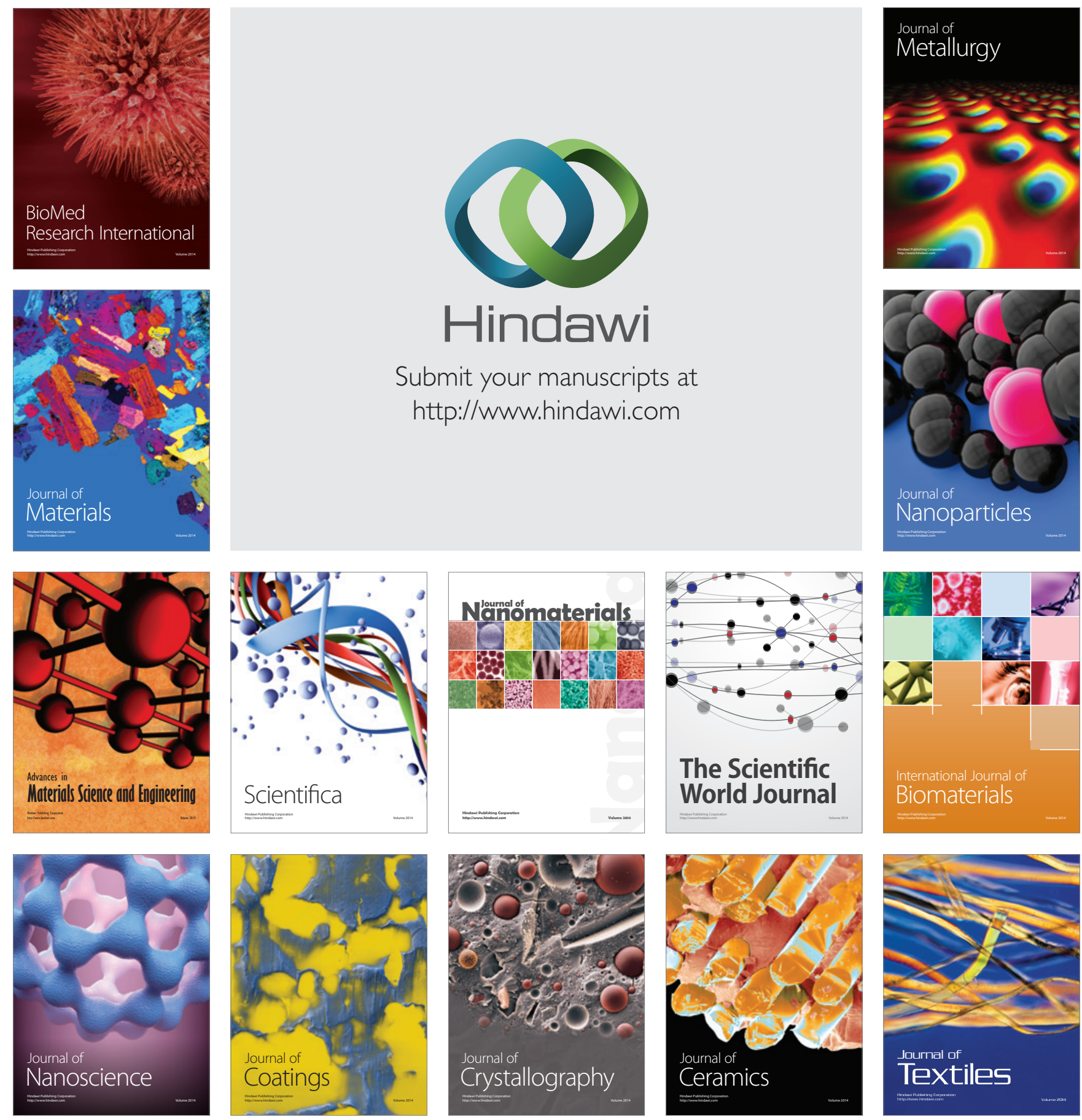